\title{
New insights into ${ }^{99} \mathrm{Tc}(\mathrm{VII})$ removal by pyrite: $\mathrm{A}$
}

\section{spectroscopic approach}

Diana M. Rodriguez ${ }^{l}$, Natalia Mayordomo ${ }^{1 *}$, Andreas C. Scheinost ${ }^{1,2}$, Dieter Schild ${ }^{3}$, Vinzenz Brendler ${ }^{l}$, Katharina Müller $^{l^{*}}$, Thorsten Stumpf ${ }^{l}$

${ }^{1}$ Institute of Resource Ecology, Helmholtz-Zentrum Dresden - Rossendorf, Bautzner Landstraße 400, 01328 Dresden, Germany

${ }^{2}$ The Rossendorf Beamline (ROBL), 71, Avenue des Martyrs, 38043 Grenoble, France

${ }^{3}$ Institute for Nuclear Waste Disposal, Karlsruhe Institute of Technology (KIT), Hermann-vonHelmholtz-Platz 1, 76344 Eggenstein-Leopoldshafen, Germany

\section{Catalogue of Supporting Information:}

Page SI 2: Detailed information about pyrite solubility determination, $X$-ray powder diffraction, $\zeta$-potential measurements, Raman microscopy and modelling, $\mathrm{pH}$ adjustment.

Page SI 5: S1. Pyrite characterization

Page SI 6: S2. pH effect on pyrite solubility

Page SI 7: S3. \% Tc released to solution during the re-oxidation essays

Page SI 8: S4. Identification of Fe(III) minerals with SEM micrographs.

Page SI 9: S5. Raman spectra of the pyrite + Tc $1000 \mathrm{ppm}$ at pH 6

Page SI 10: S6. Shell fit of the sorption complex

Page SI 11: S7. Calculated iron speciation

Page SI 12: S8. S 2p XPS spectra

Page SI 13: S9. Isotherms

Page SI 14: References 


\section{Detailed information about pyrite solubility determination, $X$-ray powder diffraction, $\zeta$-potential measurements, Raman microscopy and modelling}

\section{Pyrite solubility.}

Eight suspensions of pyrite in water $\left(1.3 \mathrm{~g} \mathrm{~L}^{-1}\right)$ were prepared and their $\mathrm{pH}$ was adjusted in the range from 3.50 to 10.50 . The samples were equilibrated under horizontal shaking for 3 weeks until the $\mathrm{pH}$ was constant. Afterwards, they were centrifuged $(600 \times \mathrm{g}$ for 1 hour) and an aliquot of $1 \mathrm{~mL}$ from the supernatants was acidified with $10 \mu \mathrm{L}$ of concentrated $\mathrm{HNO}_{3}$. The $\mathrm{Fe}^{2+}$ concentration in each sample was measured by inductively coupled plasma mass spectroscopy, ICP-MS (NexION 350x, Perkin Elmer).

\section{X-ray powder diffraction (XRD)}

The synthetic pyrite powder was analyzed by XRD (MiniFlex 600 powder XRD, by Rigaku) using $\mathrm{Cu}$ $\mathrm{K} \alpha(\lambda=1.54184 \AA)$ as $\mathrm{X}$-ray source, that has an X-ray generation of $40 \mathrm{kV} / 15 \mathrm{~mA}(600 \mathrm{~W})$. The spectrum was recorded in a scan continuous mode. The sample preparation was carried out inside a $\mathrm{N}_{2}$ glove box, where the solid was homogenized with an agate mortar and then mounted on an air-tight sample holder (Rigaku) to ensure the inert conditions of the sample during the measurement.

\section{$\zeta$-potential measurements}

In a $\mathrm{N}_{2}$ glove box, $0.05 \mathrm{~g} \mathrm{~L}^{-1}$ pyrite suspensions were prepared in $0.1 \mathrm{M} \mathrm{NaCl}$ between $\mathrm{pH} 3.00$ and $\mathrm{pH}$ 10.50. Subsequently, aliquots of the suspension were transferred into disposable cuvettes (DTS1070, Malvern). The cuvettes were taking out of the glovebox, where the $\zeta$-potential measurements were rapidly performed (Zetasizer Nano Series Nano-ZS, Malvern Instruments) at $25^{\circ} \mathrm{C}$. Five different scans 


\section{New insights into ${ }^{99} \mathrm{Tc}(\mathrm{VII})$ removal by pyrite: A spectroscopic approach (SI)}

of 30 seconds were carried out for every sample. The presented values are calculated as an average of the five independent measurements.

Raman microscopy. The samples used for these experiments come from the preparation described in the XPS section. Approximately $10 \mu \mathrm{L}$ of the re-suspension were deposited on a $\mathrm{CaF}_{2}$ Raman window under inert atmosphere. Once the solid was dry, the cell was sealed to ensure inert atmosphere during the measure. Raman microscopy (Horiba, model Aramis) was performed using a $\mathrm{He}-\mathrm{Ne}$ Laser with a 10fold objective with a D 0.3 filter, a pin-hole of $500 \mu \mathrm{m}$ and a slit of $600 \mu \mathrm{m}$.

Modeling. Fe speciation calculations were performed by using the code CHESS v $2.4^{1}$ and the two latest reported thermodynamic databases of $\mathrm{Fe}$ and $\mathrm{Tc}^{2,3}$

pH adjustment. Preliminary essays showed that with no further treatment, the $\mathrm{pH}$ of the pyrite suspension was not stable in the range from 5.50 to 8.50 , as it always became acidic due to the pyrite oxidation. ${ }^{4}$

In order to solve this problem, we decided to adjust the $\mathrm{pH}$ of all samples two times a week for the duration of the experiments, because in this range of time the variation of $\mathrm{pH}$ was already $\pm 0.15 \mathrm{pH}$ units. To do so, small amounts of $2 \mathrm{M} \mathrm{NaOH}$ and/or $\mathrm{HCl}$ were added to the systems when required. The added volume did not exceed $10 \mu \mathrm{L}$, which ensured that the variation on Tc concentration and ionic strength was small enough to be neglected, having in mind that the volume of the samples was $32 \mathrm{~mL}$ and that the pyrite removed almost $100 \%$ of the Tc after one day, meaning that only the first $\mathrm{pH}$ adjustment was performed before the completion of the reaction.

Table $\mathrm{S} 1$ is an example of the $\mathrm{pH}$ adjustment for the kinetics experiments. As can be seen, the standard deviation (SD) of the $\mathrm{pH}$ of the samples in the problematic range from 5.50 to 8.50 after the $\mathrm{pH}$ 
New insights into ${ }^{99} \mathrm{Tc}(\mathrm{VII})$ removal by pyrite: A spectroscopic approach (SI) adjustment is comparable with the $\mathrm{SD}$ of the $\mathrm{pH}$ of the samples whose $\mathrm{pH}$ did not change in a significant way.

Table S1. pH values of the kinetics experiments.

\begin{tabular}{cccccccccc}
\hline Day 1 & Day 3 & Day 7 & Day 14 & Day 21 & Day 24 & Day 35 & Day 42 & $\begin{array}{c}\text { pH } \\
\text { average }\end{array}$ & $\begin{array}{c}\text { Standard } \\
\text { Deviation }\end{array}$ \\
\hline 3.56 & 3.57 & 3.58 & 3.67 & 3.63 & 3.64 & 3.58 & 3.61 & 3.60 & 0.04 \\
4.56 & 4.61 & 4.58 & 4.68 & 4.68 & 4.63 & 4.53 & 4.59 & 4.61 & 0.05 \\
5.4 & 5.55 & 5.54 & 5.69 & 5.52 & 5.66 & 5.5 & 5.59 & 5.56 & 0.08 \\
6.67 & 6.42 & 6.57 & 6.62 & 6.59 & 6.6 & 6.62 & 6.54 & 6.58 & 0.07 \\
7.43 & 7.44 & 7.55 & 7.55 & 7.62 & 7.55 & 7.48 & 7.56 & 7.52 & 0.06 \\
8.45 & 8.58 & 8.4 & 8.57 & 8.59 & 8.57 & 8.63 & 8.54 & 8.54 & 0.07 \\
9.51 & 9.49 & 9.49 & 9.58 & 9.49 & 9.50 & 9.50 & 9.58 & 9.52 & 0.04 \\
10.61 & 10.62 & 10.62 & 10.62 & 10.52 & 10.52 & 10.57 & 10.6 & 10.58 & 0.04 \\
\hline
\end{tabular}




\section{Pyrite characterization.}
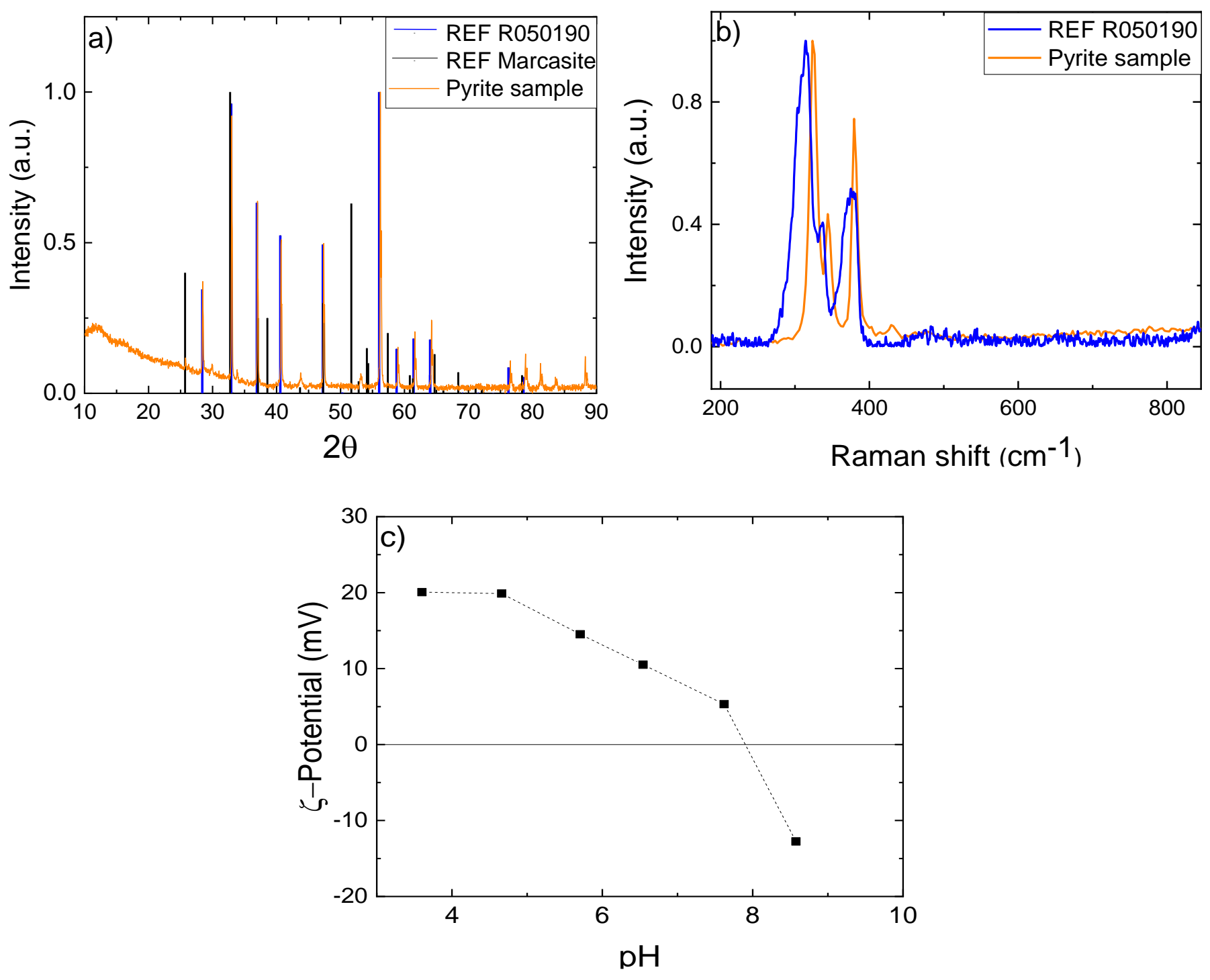

S1. Pyrite characterization experiments. a) Powder XRD, b) Raman microscopy and c) $\zeta$-potential measurements. The references are taken from the RRUFF ${ }^{\mathrm{TM}}$ database. ${ }^{5}$ 
New insights into ${ }^{99} \mathrm{Tc}(\mathrm{VII})$ removal by pyrite: A spectroscopic approach (SI)

\section{pH effect on pyrite solubility}

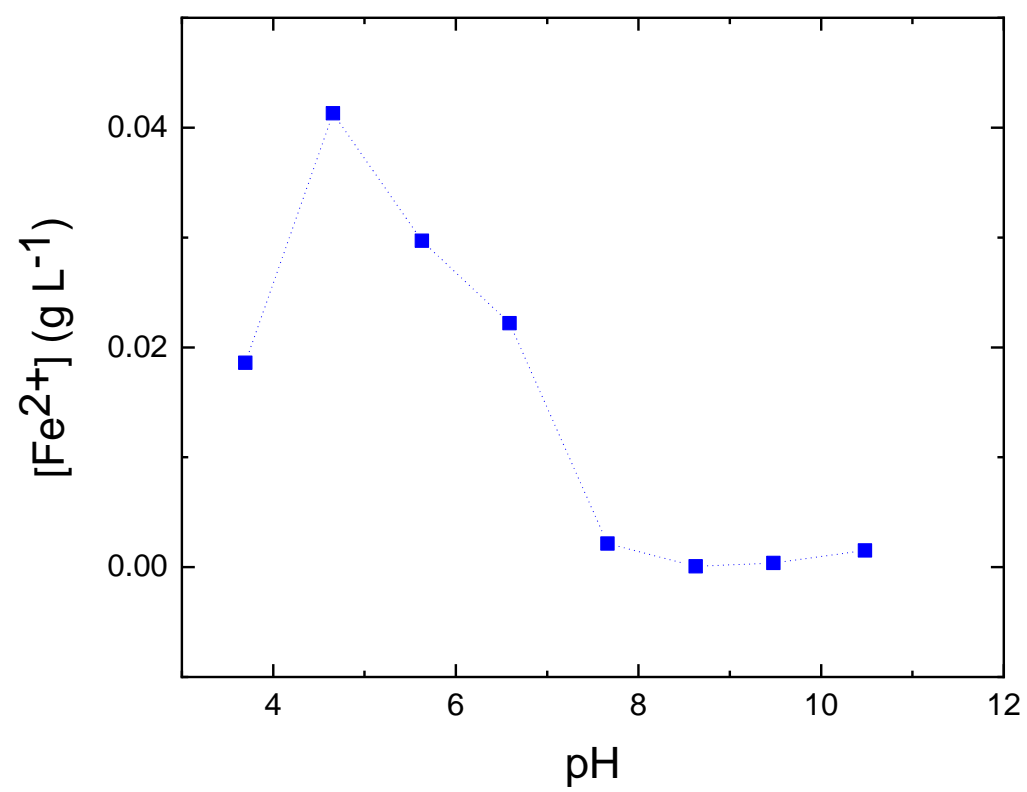

S2. Pyrite solubility measured as Fe concentration as a function of pH studied by ICP-MS (NexION 350x, Perkin Elmer). 
New insights into ${ }^{99} \mathrm{Tc}(\mathrm{VII})$ removal by pyrite: A spectroscopic approach (SI)

\% Tc released to solution during the re-oxidation essays

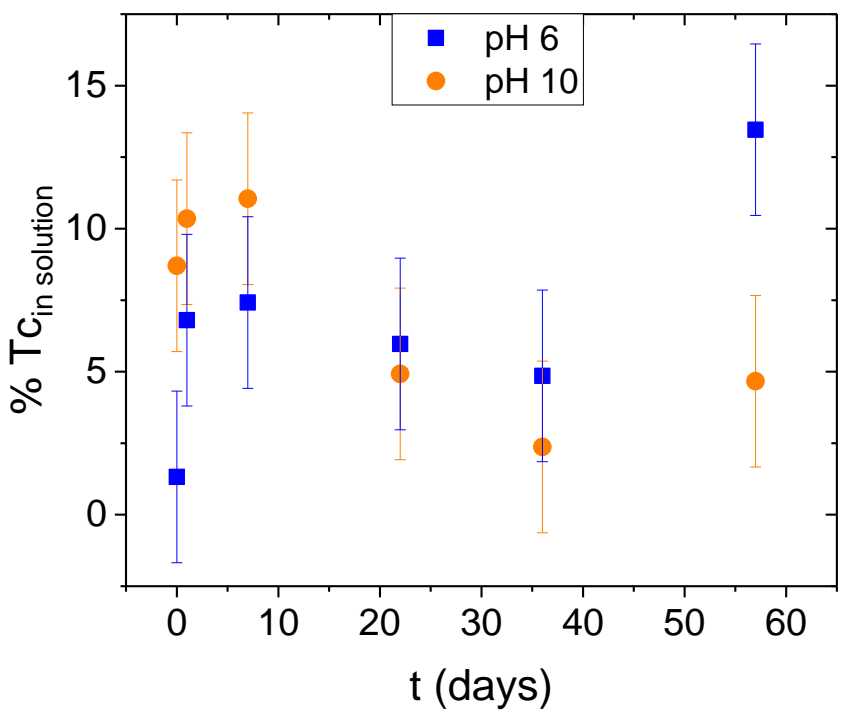

S3. \% Tc in solution in the re-oxidation essays performed for 2 months at $\mathrm{pH} 6.00$ and $10.00 . \% \mathrm{Tc}$ in solution has been calculated on the basis that the initial Tc concentration $(5 \mu \mathrm{M})$ is $100 \%$ of the Tc that might be re-mobilized if re-oxidation occurred in contact with $\mathrm{O}_{2}$, so the Tc in solution at each time (determined with LSC) is a percentage of this initial Tc concentration. 
Identification of $\mathrm{Fe}($ III) minerals with SEM micrographs.
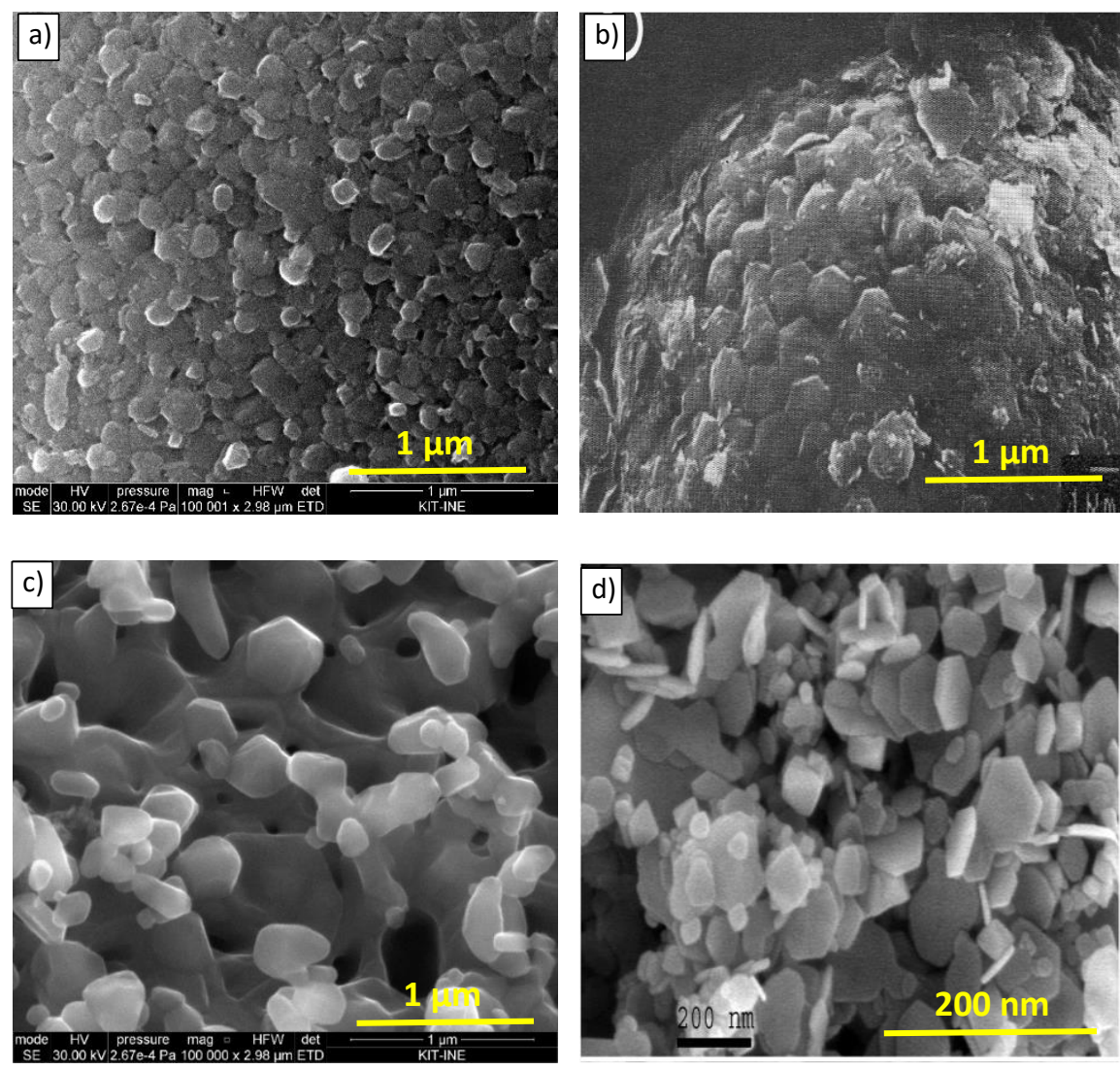

S4. Comparison between the micrographs obtained in this work and the micrographs reported by Taitel-Goldman ${ }^{6}$ : (a) this work $\mathrm{pH} 6.00 \pm 0.07$ (b) hematite formed by recrystallization of large cubic pyrite crystals ${ }^{6}$ (c) this work $\mathrm{pH} 10.00 \pm 0.04$ (d) synthesized magnetite at $70^{\circ} \mathrm{C} \mathrm{pH} 9.4$ and a solution of $4 \mathrm{M} \mathrm{NaCl}^{6}$. 


\section{Raman spectra of the pyrite $+\mathrm{Tc} 1000 \mathrm{ppm}$ at $\mathrm{pH} 6$}

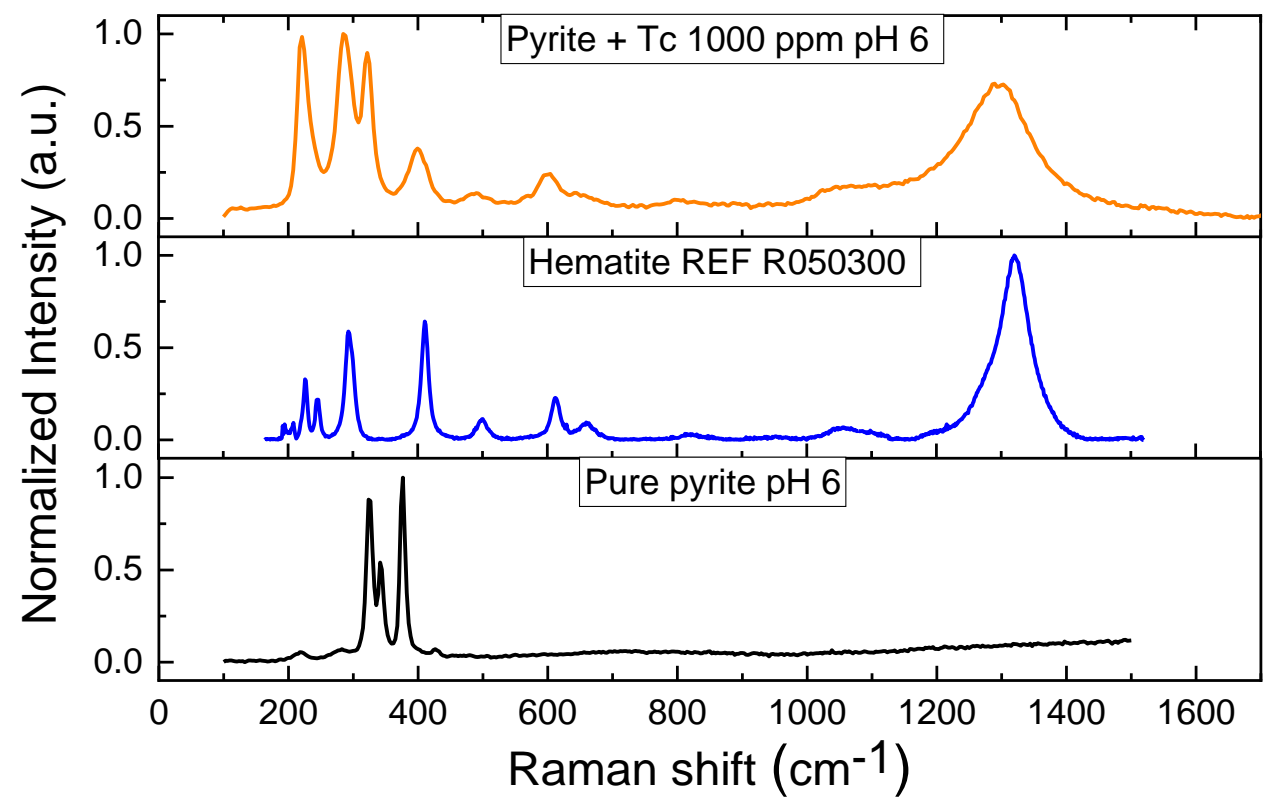

S5. Raman spectra of the pyrite containing $1000 \mathrm{ppm}$ Tc load at $\mathrm{pH} 6.00 \pm 0.07$ compared with the hematite reference R050300 of the RRUFF ${ }^{\mathrm{TM}}$ database ${ }^{5}$ and the spectra of a sample of pyrite at $6.00 \pm$ 0.07 obtained by this work. 
New insights into ${ }^{99} \mathrm{Tc}(\mathrm{VII})$ removal by pyrite: A spectroscopic approach (SI)

\section{Shell fit of the sorption complex}

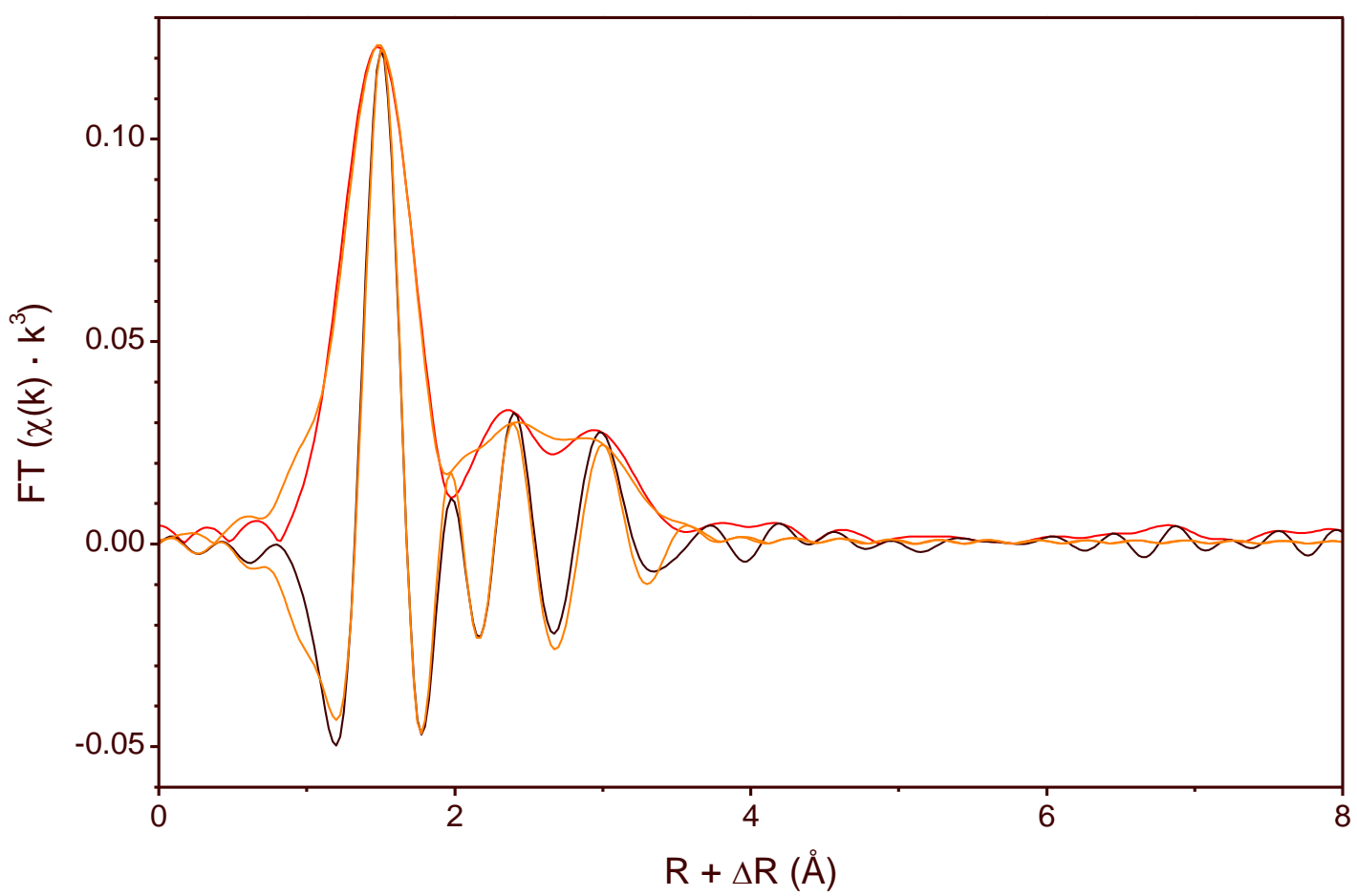

S6. Shell fit of species 1, the sorption complex. 


\section{Calculated iron speciation}

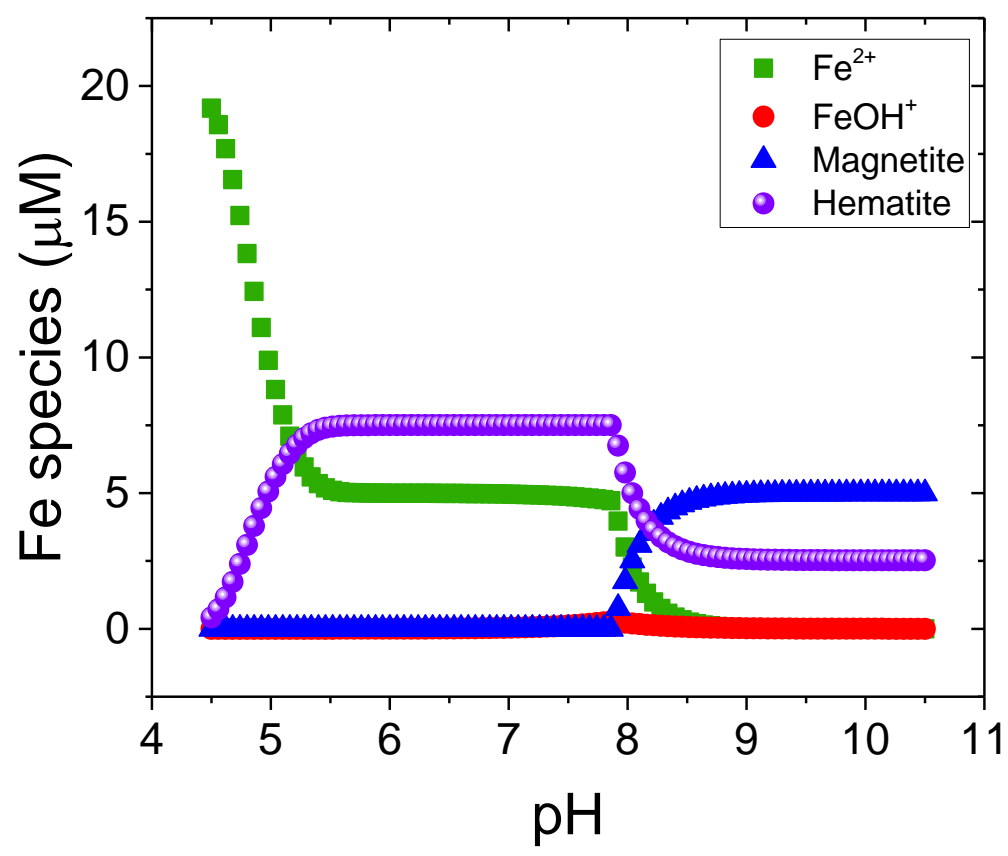

S7. Iron speciation as a function of $\mathrm{pH}$. Calculations have been performed considering the initial presence of $20 \mu \mathrm{M} \mathrm{Fe}^{2+}$ and $5 \mu \mathrm{M} \mathrm{TcO}_{4}{ }^{-}$. The latest $\mathrm{Fe}^{2}$ and $\mathrm{Tc}^{3}$ thermodynamic databases have been used. 
New insights into ${ }^{99} \mathrm{Tc}(\mathrm{VII})$ removal by pyrite: A spectroscopic approach (SI)

\section{S 2p XP spectra}

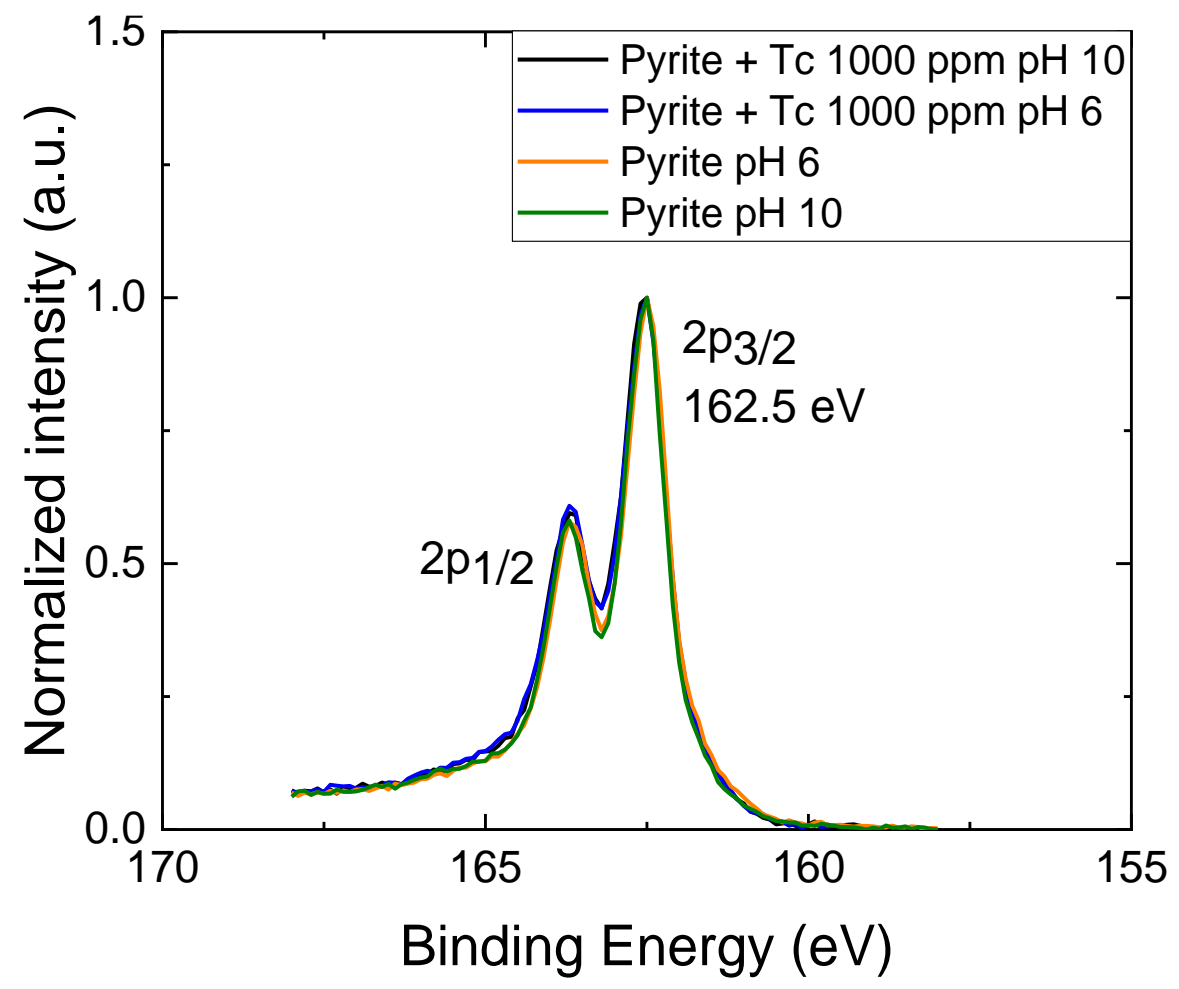

S8. S 2p XP spectra of pyrite after the reaction with Tc(VII) at pH $6.00 \pm 0.07$ and $10.00 \pm 0.04$. 


\section{Isotherms}

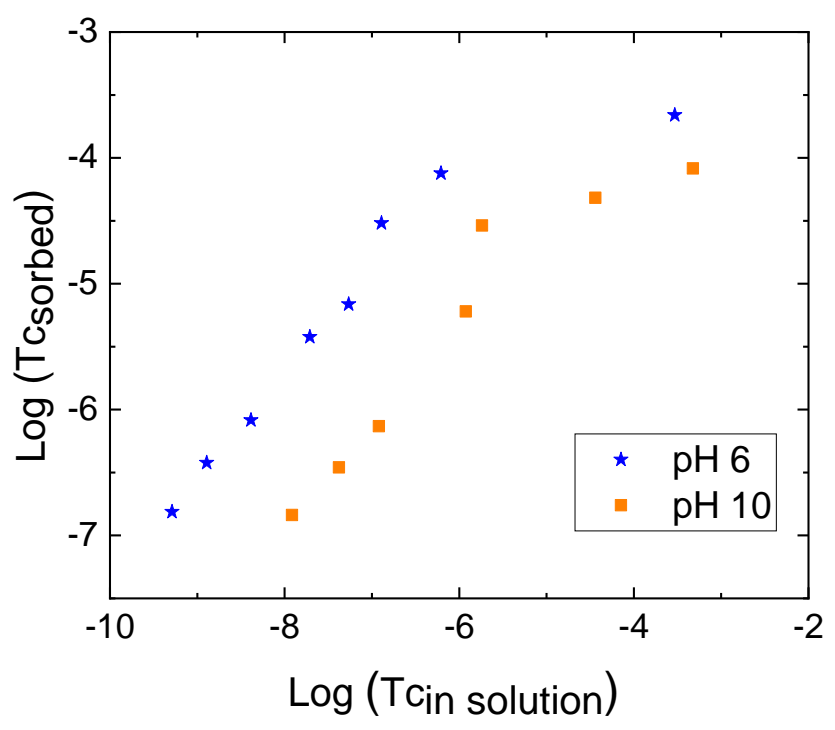

S9. Isotherms of the Tc immobilization by pyrite at $\mathrm{pH} 6.00 \pm 0.07$ and $10.00 \pm 0.04$. The $\mathrm{Tc}_{\text {in solution }}$ is given by converting the activity of the sample (measured by LSC) from Bq $\mathrm{mL}^{-1}$ to $\mathrm{mol} \mathrm{L}^{-1}$. The

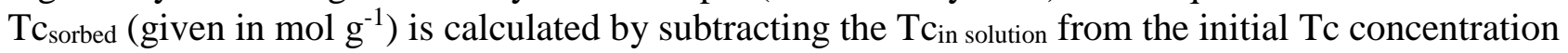
$\left(5 \cdot 10^{-6} \mathrm{~mol} \mathrm{~L}^{-1}\right)$ and dividing the result by the pyrite suspension concentration $\left(1.3 \mathrm{~g} \mathrm{~L}^{-1}\right)$. 


\section{References}

(1) van der Lee, J.; de Wint, L. Chess Tutorial and Cookbook, Technical Report LHM/RD/99/05. 1999.

(2) Lemire, R. J.; Berner, U.; Musikas, C.; Palmer, D. A.; Taylor, P.; Tochiyama, O. Chemical Thermodynamics of Iron. Part 1, OECD Nuclear Energy Agency.; OECD: Paris, France, 2013; Vol. 13a.

(3) Guillaumont, R.; Fanghänel, T.; Neck, V.; Fuger, J.; Palmer, D. A.; Grenthe, I.; Rand, M. H. Update on the Chemical Thermodynamics of Uranium, Neptunium, Plutonium, Americium and Technetium; Mompean, F. J., Illemassene, M., Domenech-Orti, C., Ben Said, K., Eds.; OECD: Issy-les-Moulineaux (France), 4, 2003.

(4) Bonnissel-Gissinger, P.; Alnot, M.; Ehrhardt, J.-J.; Behra, P. Surface Oxidation of Pyrite as a Function of pH. Environ. Sci. Technol. 1998, 32 (19), 2839-2845. https://doi.org/10.1021/es980213c.

(5) Lafuente, B.; Downs, R. T.; Yan, H.; Stone, N. The Power of Databases: The RRUFF Project. In Highlights in Mineralogical Crystallography; De Gruyter: Berlin, 2015; pp 1-30.

(6) Taitel-Goldman, N. Recrystallization Processes Involving Iron Oxides in Natural Environments and In Vitro; IntechOpen: Rijeka, 2013; p Ch. 6. https://doi.org/10.5772/53735. 